\title{
Assistência Social e Juventude:
}

reflexões acerca das políticas públicas para os jovens brasileiros.

\section{Afonso Vieira Lino Filho}

Mestre em Planejamento em Políticas Publicas - UECE

\section{Lia Machado Fiuza}

Doutora em Educação pela Universidade Federal do Ceará - UFC

Professora do Programa de Pós-Graduação em Educação (PPGE) da UECE

\section{Resumo}

Este artigo tem como objetivo apresentar o processo de implementação durante os onze anos de debates acerca das políticas de Assistência Social e Juventude no Brasil como política de proteção social. Iremos

apresentar a partir dos seus aspectos normativos e conceituais o debate que vem sendo realizado no nestes onze anos de construção, a relevância consiste em contribuir com a produção de pesquisa nas áreas de Assistência Social e Juventude ao desvelar como se efetiva uma política social oferecido para sociedade pelo Estado.

Palavras-chave: Políticas públicas. assistência social. juventude 


\section{Abstract}

This article aims to present the implementation process during the eleven years of debates about Social policy and Youth in Brazil as social protection policy. We will present from its normative and conceptual aspects of the debate that has been conducted in these eleven years of construction, the relevance is to contribute to the production of research in the areas of Social Assistance and Youth at the unveiling as a social policy becomes effective provided to society by the State.

Keywords: public policy. social assistance. Youth 


\section{Introdução}

Assistência Social como política pública deu-se a partir da constituição de 1988, sob a óptica de cidadania. Como política pública, a Assistência Social inicia um novo percurso, o caminho dos direitos, do acesso direto sem a intermediação centralizada de prefeitos, primeiras damas e vereadores. Observamos, também, neste período, a universalização dos serviços, além, claro da responsabilidade estatal restringindo a influência e a responsabilidade das entidades pela condução da política. Podemos também destacar que neste momento inicia um processo de política de proteção social articulada a outras políticas públicas objetivando a garantia de direitos, sem o cunho meramente assistencialista das populações em vulnerabilidade social 1 .

A política de Assistência Social nos últimos onze anos, desde a implantação do Sistema Único de Assistência Social (SUAS) no ano de 2005, passou por um processo de reestruturação que rompeu com o conservadorismo histórico, construindo formas de políticas públicas voltadas para as camadas mais vulneráveis do Brasil, e as cidades de Fortaleza como em Maracanaú no Estado do Ceará Ceará estão neste contexto de totalidade no qual devemos a cada momento, dialogar com as pessoas que recebem este serviço e assim avaliar se a política pública que se propõe a realizar tem realmente o resultado obtido.

O presente artigo está intimamente apoiado nas inquietações que emergiram de nossas experiências com a juventude e vivenciada como orientador social, porém, é necessário que algumas categorias sejam elencadas como fundamentais para compreensão deste trabalho. Uma delas é a Política Pública, tão debatida e cobrada pela população, esta categoria é basilar em nosso estudo por apresentar a concepção de como podemos proceder aos inúmeros casos de omissão em áreas importantes como saúde, educação, assistência social dentre outras. É essencial a compreensão sobre esta categoria, por ser necessária sua compreensão de Estado, possibilitando neste trabalho o debate, essa compreensão é necessária para entendimento do poder político e das atividades produtivas e econômicas deste Estado.

O interesse em pesquisar essas duas categorias - Assistência Social e Juventude decorreram do fato de ambas fortalecerem as políticas de proteção social além de essenciais para efetivação de direitos dos jovens em todo o Brasil. A Política Nacional de Juventude (PNJ), bem como a Política Nacional de Assistência Social (PNAS), se consolidaram nesses últimos 11 (onze) anos, tornando pertinente ensejar reflexões de tais políticas para que possamos dialeticamente apresentar os referenciais teóricos pesquisados neste trabalho.

Com a temática juventude sendo debatida em nossa sociedade recentemente, propomos indagar sobre qual lugar social está reservado aos jovens. Para isso, é necessário considerar suas

1 Na análise de Robert Castel (1998) o conceito de vulnerabilidade social está localizado na chamada "sociedade salarial", que discute sobre aqueles que se encontram "desfiliados", ou seja, estão à margem da sociedade. Para o Autor, "desfiliação" indica desemprego, subemprego, emprego mal-remunerado, precarizado, sem proteção (social e previdenciária). Deste modo, a precariedade social pode desencadear um processo de exclusão social e assim sendo, o conceito desfiliados relaciona-se ao aumento de vulnerabilidade social, devido ao rompimento dos laços sociais. 


\section{Afonso Vieira Lino Filho/ Lia Machado Fiuza Fialho}

falas e experiências, salientamos a importância do tema para a pesquisa e para o conhecimento científico nos bancos acadêmicos:

Assim, nos tempos atuais, colocar os jovens no foco do conhecimento científico é estratégico e essencial para que se possa apostar em sociedades mais justas no acesso ao bem-estar e à participação cidadã, por meio de maior equidade e igualdade de oportunidades. Desse modo, possibilitam-se maiores níveis de inclusão social dos jovens e instruem-se práticas de integração dessa população nas redes de promoção social (educação, trabalho, cultura, comunicação etc.). Sem dúvida, garantir direitos e ampliar oportunidades constitui a chave mestra para imprimir sustentabilidade à democracia em nosso país. (HENRIQUES; NOVAES, 2007, p.07)

Assim tanto a PNAS quanto a PNJ tem o desafio de incluir os jovens nas políticas públicas de Assistência Social e Juventude, um desafio que se apresenta quando da votação da PEC 55 ${ }^{2}$ no Senado Federal que congela por 20 anos os investimentos sociais. Dialogamos então com estas duas políticas para a melhoria de suas vidas, ante a problemática elencada, percebemos como afirma o autor Gil (2008) que a relevância da pesquisa está nos benefícios que decorrem da solução de sua problemática e resposta ao objetivo proposto. Sabe-se, pois, que os usuários ponderam se beneficiar com as mudanças oriundas da melhoria do serviço ou no aperfeiçoamento da sua gestão, que oportunizará a realização de um melhor serviço. Essa discussão da aplicação dos aprendizados proporcionados pela pesquisa científica, na prática, é fundamental para traçar caminhos metodológicos para nossa pesquisa. Ainda segundo Gil (2008):

\footnotetext{
A relevância prática do problema está nos benefícios que podem decorrer de sua solução. Muitas pesquisas são propostas por órgãos governamentais, associações de classe, empresas, instituições educacionais ou partidos políticos, visando à utilização prática de seus resultados. Assim, o problema será relevante à medida que as respostas obtidas trouxerem consequências favoráveis a quem o propôs.Ao se falar da relevância prática do problema, cabe considerá-la também do ponto de vista social. Neste sentido, várias questões podem ser
}

2 Proposta de Emenda à Constituição n 55, de 2016 - PEC do teto dos gastos públicos: Institui o novo regime fiscal no âmbito dos Orçamentos Fiscal e da Seguridade Social da União, que vigorará por 20 exercícios financeiros, existindo limites individualizados para as despesas primárias de cada um dos três Poderes, do Ministério Público da União e da Defensoria Pública da União; sendo que cada um dos limites equivalerá: I - para o exercício de 2017, à despesa primária paga no exercício de 2016, incluídos os restos a pagar pagos e demais operações que afetam o resultado primário, corrigida em 7,2\% e II - para os exercícios posteriores, ao valor do limite referente ao exercício imediatamente anterior, corrigido pela variação do Índice Nacional de Preços ao Consumidor Amplo - IPCA. Determina que não se incluem na base de cálculo e nos limites estabelecidos: I - transferências constitucionais; II - créditos extraordinários III - despesas não recorrentes da Justiça Eleitoral com a realização de eleições; e IV - despesas com aumento de capital de empresas estatais não dependentes. Fonte: Senado Federal 
formuladas: Qual a relevância do estudo para determinada sociedade? Quem se beneficiará com a resolução do problema? Quais as consequências sociais do estudo? Entretanto, esta discussão torna-se importante à medida que ajuda a explicitar as direções possíveis de uma investigação e suas diferentes consequências. (GIL, 2008, p.35)

Acreditamos, com efeito, que através deste estudo se possa lançar luz a novos olhares e ações práticas, que possam considerar a inclusão do jovem como sujeito capaz de contribuir com a formulação, junto ao Estado, de políticas públicas que atendam às suas necessidades. Esclarecido que o trabalho apresentado versa sobre às políticas públicas de Assistência Social e Juventude, ao tecer reflexões sobre tais políticas reafirmamos a importância destas para a redução das inúmeras expressões da questão social no Brasil.

Consideramos que pesquisar a PNAS e a PNJ é tentar compreender as idas e vindas da construção destas duas políticas públicas como garantidora de direitos, contudo, ainda lutando contra o víeis assistencialista que vez em quando tenta se apropriar em alguns municípios de nosso Brasil, por isso é necessária sua compreensão para que possamos estabelecer um esforço continuo pelo fortalecimento de seus programas, projetos, benefícios e serviços. Realizamos uma explanação panorâmica das políticas públicas para as juventudes no Brasil manifestadas nos últimos anos e desenvolvidas pelo Estado além do constructo juventudes, afirmamos que são políticas em construção.

\section{A contribuição da assistência social com as juventudes}

É necessário compreender a importância de políticas públicas para a juventude, para desvendar a multiplicidade de ser jovem e, assim identificar as políticas públicas que propiciam aos jovens, de uma forma em geral, sua independência como sujeitos ativos que participam e que compõem a sociedade. A contribuição da Política de Assistência Social se dá na implementação do Programa Agente Jovem em 2005 e posteriormente em 2007 com o Projovem Adolescente. As primeiras leituras sobre o Projovem Adolescente que se deu no ano de 2007 nos fizeram refletir como este serviço é importante para o auxílio na construção da cidadania dos jovens que estão em território de vulnerabilidade social, onde as políticas públicas se fazem necessárias.

O programa foi instituído pela medida provisória no 411 de 28 de dezembro de 2007. Originou-se de uma reformulação do programa agente jovem e insere-se no contexto da Assistência Social (PNAS) e de Juventude (PNJ), elaborada pelo Governo Federal. Destina-se aos jovens de 15 a 18 anos ditos em situação de vulnerabilidade social, pertencentes às famílias beneficiárias do 
programa Bolsa Família, egressos de medidas socioeducativas, conforme disposto na Lei no 8.069 de 13 de julho de 1990 - Estatuto da Criança e do Adolescente (ECA), ou em cumprimento e egressos do Programa de Erradicação do Trabalho Infantil.

Segundo os traçados metodológicos, trata-se de um serviço socioeducativo com o objetivo central de proporcionar capacitação teórica e prática aos jovens, por meio de atividades socioeducativas, mas que possibilitam a permanência destes no sistema de ensino e no fortalecimento dos vínculos familiares e comunitários, de forma a prepará-los para futuras inserções no mundo do trabalho. Interessante também é compreender que o Projovem Adolescente faz parte do Programa Nacional de Inclusão de Jovens, conhecido como Projovem. Dentro desse novo contexto da política de Assistência Social, este serviço passa a ser ofertado nos CRAS e nas redes socioassistenciais.

Assim, tanto a política de Assistência Social como a política de juventude deve trabalhar não tendo o jovem como um problema social, mais como garantidor de direitos e um fator de importância na construção das políticas públicas nestes onze anos foi sobre a participação do usuário, é de fundamental importância que o Estado possa ouvir a juventude, contudo, parece ainda algo distante para o Estado, a autora Abramo (1997) nos fala do enfretamento do jovem como problema:

\footnotetext{
No entanto, pode-se dizer que a maior parte desses programas está centrada na busca de enfrentamento dos "problemas sociais" que afetam a juventude, mas no fundo tomando os jovens eles próprios como problemas sobre os quais é necessário intervir para salvá-los e reintegra-los à ordem social". (ABRAMO,1997, p.26)
}

Podemos afirmar que nestes onze anos destas políticas tivemos a criação de espaços para nossas juventudes além da escola, pela Assistência Social temos o Serviço de Convivência Adolescente (nomenclatura utilizada desde 2013 em substituição ao Projovem Adolescente) e pela Política de Juventude temos o Estação Juventude. Propiciar locais de convivência deve ser garantido pelo Estado nas políticas públicas:

A percepção dessa necessidade de uma vida social para além da escola, por parte dos jovens, ao lado da percepção dos perigos existentes nas ruas, é que normalmente monta a equação pela qual os poderes públicos têm buscado dar respostas por meio de montagem de equipamentos que se oferecem como "espaços para os jovens" e mais recentemente surge à percepção da importância de dirigir outros tipos de programas e serviços de apoio aos jovens e assim participar dos processos de definição e decisão políticas. (ABRAMO, 1997, p.223) 
Nessa conjuntura, o Serviço de Convivência Adolescente é fundamental como política pública, pois, por intermédio dele podemos compreender que existem programas de inclusão, ou de tentativa de inclusão dos jovens como foco de ações das políticas públicas. Importa considerar, no entanto, o próprio programa possui regras que ao tempo em que visa incluir a juventude no programa, também exclui a partir dos critérios estabelecidos para o seu ingresso.

Existe, assim, a exclusão de regras de políticas públicas organizadas pelo próprio Estado. E ao mesmo tempo o movimento de inclusão de outras políticas sociais pelo mesmo Estado, ou seja, apenas os jovens considerados a margem da sociedade (que cometeram infração) e os que se encontram em situações de vulnerabilidades são assistidos, tantos outros fatores poderiam ser considerados, como o uso de drogas, a violência, o desemprego, dentre outros, mas para esses aspectos há a justificativa de que devem ter ações específicas para este segmento na implementação de políticas públicas, outras ações podem e devem ser realizadas, mas observa-se a falta de articulação entre os programas e projetos.

O Serviço de Convivência Adolescente insere-se no contexto das políticas públicas voltadas à redução da pobreza e ao enfrentamento das desigualdades sociais, metas que concorre para alcançar, ao investir na formação social e humana do jovem e incentivar o aumento de sua escolaridade, gerando mais oportunidades de integração social e de ingresso futuro em melhores condições no mundo do trabalho (MDS, 2009). O Estado é o grande fiador desta e de outras políticas sociais, FALEIROS (2009, p.49) afirma: "o Estado é assim considerado como o agente principal que age pela sociedade civil, para tornar acessivel este mínimo para "proteção" material dos indivíduos".

Essa concepção do Estado se traduz por uma série de medidas para possibilitar a acessibilidade a esse mínimo: eliminação das barreiras geográficas pela descentralização, das barreiras financeiras pelas transferências, e das barreiras técnicas pela racionalização. Nesse sentido, precisa-se dar um mínimo social à população para garantir a eficiência da economia é o que destaca a política de hoje. Claro que não podemos ignorar a ideia do reconhecimento constitucional desta política social (SUAS, LOAS, Tipificação 2009), que foi um avanço, mas importa perceber que a dialética com a economia e a instância do poder político interpreta e reflete a base econômica.

Embora afirmando os direitos dos segmentos mais pobres, as lutas e negociações por parte da sociedade organizada, prosseguem até os dias atuais as severas desigualdades e não são essas políticas isoladamente que conseguiram reverter esse quadro socioeconômico. Lutar sempre pelo direito dos trabalhadores mais oprimidos e da população em desvantagem nas condições de ascensão é preciso. Nesse sentido, a política social da Assistência deve ser um direito de todos.

Outro arcabouço que contribui com o Serviço de Convivência é a Lei Orgânica da Assistência Social - LOAS, sua implementação foi no dia 07 de dezembro de 1993, sendo instituída pela Lei 8.742, que estabelece normas e critérios para organização da Assistência Social. Como é um direito dos usuários desta política, a importância da LOAS é significativa pois vai proporcionar definição de leis, normas e critérios objetivos desta política além de subsidiar elementos legais para aprimorar os serviços para a população. 
A Política de Assistência Social - LOAS, lei 8742 de 07 de dezembro de 1993 - em seu artigo primeiro garante:

Art. 1ํ A assistência social, direito do cidadão e dever do Estado, é Política de Seguridade Social não contributiva, que provê os mínimos sociais, realizada através de um conjunto integrado de ações de iniciativa pública e da sociedade, para garantir o atendimento às necessidades básicas.

O importante analisar é que a Constituição trouxe para a discussão política e para a sociedade, o reconhecimento de direitos que ao longo da história brasileira foram negados pelo Estado. Outro ponto importante é trazer o debate da pobreza e de toda forma de desigualdade social, tornando possível transformar o assistencialismo ou a ação social em uma política garantidora das políticas sociais e de direitos, sem a característica de favor. O Serviço de Convivência Adolescente, então, tem sua primeira contribuição como política pública vinculada a Proteção Social Básica inserida na Política de Assistência Social. Logo, clarifica-se que caso não existisse a vinculação desta seguridade social e a criação de tais políticas, dificilmente teríamos o Serviço de Convivência realizado nos CRAS e Centro de Convivência Social no Brasil.

O Estatuto da Criança e do Adolescente - ECA, aprovado em 13 de julho de 1990 pela Lei 8.069, também proporciona aos usuários do Serviço de Convivência, que são os adolescentes, amplos direitos até então negados para esta categoria. A proteção integral ensejada pelo ECA é fundamental para o processo de crescimento e aprendizagem, com isso este Estatuto tenta garantir a liberdade e dignidade para crianças e adolescentes. Salientamos que este documento é um instrumento de cidadania, para além de regulador de direitos e deveres.

Outro aspecto de contribuição para o Serviço de Convivência Adolescente no Brasil foi a implementação, em 2005, do Sistema Único de Assistência Social (SUAS), no qual o atendimento e acompanhamento às famílias em vulnerabilidade social e a potencialização da política no território da população foram asseguradas. Os adolescentes são prioridade na construção desta política. O desafio então era elaborar marcos regulatórios para distanciar a ideia do assistencialismo e a do voluntariado, que por muitos anos eram ações embasadas nessas concepções que conduziam a Política de Assistência Social.

Segundo o SUAS (BRASIL, 2005, p.14) são eixos estruturantes:
a. Precedência da gestão pública da política;
b. Alcance de direitos sócio assistencial pelos usuários;
c.Matricialidade sociofamiliar; 


\author{
d.Territorialização; \\ e. Descentralização político-administrativa; \\ f. Financiamento partilhado entre os entes federados; \\ g. Fortalecimento da relação democrática entre Estado e Sociedade Civil; \\ h. Valorização da presença do controle social; \\ i. Participação popular/cidadão usuário; \\ j. Qualificaçãode recursos humanos; \\ k. Informação, monitoramento, avaliação e sistematização de resultados.
}

O SUAS proporcionou o fortalecimento da LOAS e consolidou a efetivação dos serviços, principalmente o de convivência que é continuado. Estes independem de governos, pois é uma política de Estado, dessa maneira, percebemos então a importância para a Assistência Social dentro da seguridade social não contributiva. O financiamento é um item fundamental para o crescimento de qualquer política pública, em especial uma política que atende a juventude. 0 financiamento possibilita a contratação de profissionais como orientadores sociais, facilitadores de cultura, esporte e informática, além de outras ferramentas de grande impacto dentro do Serviço de Convivência Adolescente.

Um dos marcos legais mais importantes para o Serviço de Convivência é a Tipificação Socioassistencial № 109 / 2009 na qual teremos pactuado todos os serviços existentes tanto na Proteção Social Básica como na Proteção Especial. A tipificação norteia o Serviço de Convivência Adolescente para uma concepção de fortalecimento de vínculos no âmbito da proteção básica de assistência social, organiza e define os usuários, e sua implementação norteia os serviços na perspectiva de proteção que pretende minimizar as situações de vulnerabilidade social vivenciadas pelos usuários.

Com a tipificação, os serviços socioassistenciais propiciaram unidades de atendimento no Brasil, devido ao seu sistema único de comando, fomentam uma convivência entre sujeitos de direitos que se constituem à medida em que se relacionam nos municípios os grupos como o PAIF. Quanto à organização dos serviços, tanto da Proteção Social Básica como da Proteção Especial, se apresenta um quadro síntese:

\title{
2. QUADRO SÍNTESE: \\ PROTEÇÃO SOCIAL BÁSICA:
}

1. Serviço de Proteção e Atendimento Integral à Família - PAIF

2. Serviço de Convivência e Fortalecimento de Vínculos

3. Serviço de Proteção Social Básica no Domicílio para Pessoas com Deficiência e Idosas 


\section{PROTEÇÃO SOCIAL ESPECIAL \\ Média Complexidade}

1. Serviço de Proteção e Atendimento Especializado a Famílias Indivíduos PAEFI

2. Serviço Especializado de Abordagem Social

3. Serviço de proteção social a adolescentes em cumprimento de medida socioeducativa de Liberdade

Assistida (LA) e de Prestação de Serviços à Comunidade (PSC)

4. Serviço de Proteção Social Especial para Pessoas com Deficiência, Idosos(as) e suas Famílias

5. Serviço Especializado para Pessoas em Situação de Rua

\section{Alta Complexidade}

6. Serviço de Acolhimento Institucional

7. Serviço de Acolhimento em República

8. Serviço de Acolhimento em Família Acolhedor

9. Serviço de proteção em situações de calamidades públicas e de emergências. (BRASIL, 2009, p. 04).

Outra ferramenta que fortalece isso dentro do Serviço de Convivência Adolescente é a Norma Operacional Básica do Sistema Único da Assistência Social - NOB/SUAS, aprovada pela Resolução no 130, de 15 de julho de 2005, do Conselho Nacional de Assistência Social (CNAS). Ela contribui com o aperfeiçoamento do Serviço de Convivência, é oriunda da Resolução no 33, de 12 de dezembro de 2012 que aprova a Norma Operacional Básica do Sistema Único de Assistência Social - NOB/SUAS 2012.

Destacamos os artigos 3ạ na página 02 que traz os princípios do SUAS, que para o Serviço de Convivência fortalece a participação do usuário, neste artigo da NOB - SUAS 2012 a universalidade é um dos pontos apresentados como fundamental para a Política de Assistência Social, vejamos:

Art. 3 São princípios organizativos do SUAS: I - universalidade: todos têm direito à proteção socioassistencial, prestada a quem dela necessitar, com respeito à dignidade e à autonomia do cidadão, sem discriminação de qualquer espécie ou comprovação vexatória da sua condição; II - gratuidade: a assistência social deve ser prestada sem exigência de contribuição ou contrapartida, observado o que dispõe o art. 35, da Lei n 10.741, de 1ำ de outubro de 2003 - Estatuto do Idoso; III - integralidade da proteção social: oferta das provisões em sua completude, por meio de conjunto articulado de serviços, programas, projetos e benefícios socioassistenciais; IV - intersetorialidade: integração e articulação da rede socioassistencial com as demais políticas e órgãos setoriais; $V$ - equi- 
dade: respeito às diversidades regionais, culturais, socioeconômicas, políticas e territoriais, priorizando aqueles que estiverem em situação de vulnerabilidade e risco pessoal e social.

Para o Serviço de Convivência Adolescente, a NOB SUAS 2012 traz possibilidades reais para a garantia de direitos dos seus usuários, pois organiza, ainda mais, a Política de Assistência Social, alargando as possibilidades do crescimento de um serviço continuado e intersetorial. Em Maracanaú destacamos a parceria constante entre o Serviço de Convivência Adolescente com as Secretarias de Juventude e Lazer, Saúde e Educação.

Um dos artigos mais importantes desta resolução é o que trata sobre as diretrizes da gestão do SUAS, porque traz e fortalece a ideia de que o Estado é o responsável por organizar e trabaIhar as Políticas Públicas e não as entidades e Organizações Não Governamentais - ONG, como era articulada a bem pouco tempo na história da Assistência Social (NOB SUAS, 2012). Destaca, também, a centralidade única de gestão para que no Brasil se trabalhe com as mesmas informações e normativas técnicas.

Outro documento fundamental para o Serviço de Convivência Adolescente é a Resolução no 01, de 21 de fevereiro de 2013, que dispõe sobre o reordenamento do Serviço de Convivência e Fortalecimento de Vínculos - SCFV, no âmbito do Sistema Único da Assistência Social - SUAS. Ela pactua os critérios de partilha do cofinanciamento federal e das metas de atendimento do público prioritário. Pactua também algumas modificações do público prioritário para atendimento, em 50 \% do atendimento do município. Importa mencionar que em 2014 a Secretaria de Assistência Social e Cidadania de Maracanaú - SASC pactuou como meta o quantitativo de dois mil quatrocentos e quarenta (2.440) atendimentos de usuários para o Serviço de Convivência criança, adolescentes e idosos, destes, mil duzentos e vinte (1.220) devem ser do público prioritário apresentado no reordenamento, vejamos:

\section{CAPÍTULO I}

Da oferta do Serviço de Convivência e Fortalecimento de Vínculos - SCFV Art. 2으 O SCFV é um serviço de proteção social básica realizado em grupos, organizado a partir de percursos, de modo a garantir aquisições progressivas aos seus usuários, de acordo com seu ciclo de vida, a fim de complementar o trabalho social com famílias e prevenir a ocorrência de situações de vulnerabilidade e risco social.

Art. 3 Considera-se em situação prioritária para inclusão no SCFV, as crianças, adolescentes e pessoas idosas: I - em situação de isolamento; II - trabalho infantil; III - vivência de violência e, ou negligência; IV - fora da escola ou com defasagem escolar superior a 2 (dois) anos; $V$ - em situação de acolhimento; VI - em cumprimento de medida socioeducativa em meio aberto; VII - egressos de medidas socioeducativas; VIII - situação de abuso e/ ou exploração sexual; 
IX - com medidas de proteção do Estatuto da Criança e do Adolescente ECA; $X$ - crianças e adolescentes em situação de rua; XI - vulnerabilidade que diz respeito às pessoas com deficiência; $\$ 1^{\circ}$ Para a identificação dos usuários em situação prioritária será utilizado o Número de Identificação Social - NIS do Cadastro Único para Programas Sociais do Governo Federal - Cadúnico. §2- A comprovação das situações prioritárias dar-se-á por meio de documento técnico que deverá ser arquivado na Unidade que oferta o SCFV ou no órgão gestor, por um período mínimo de cinco anos, à disposição dos órgãos de controle. $\S 3^{\circ}$ Estabelece-se como meta de atendimento de 50\% (cinquenta por cento), no mínimo, do público prioritário. (RESOLUÇÃO no 01, 2013, p.02)

Percebemos então que os onzes anos da Política de Assistência Social foram de crescimento pautado pelo direito, inclusão e uma visão técnica da política pública, a inclusão dos jovens pelo serviço de convivência traz em pauta a possibilidade de inclusão destes jovens em oficinas socioeducativas, culturais, esportivas e de inclusão tecnológica, no próximo tópico iremos apresentar ferramentas de fortalecimento da Política de Juventude no Brasil nestes onze anos, contudo percebemos que estamos distantes da efetivação dos direitos implantados como afirma o ECA e o Estatuto de Juventude.

\section{A construção da política de juventude no Brasil}

Esta categoria vem sendo mais amplamente debatida e estudada a partir do século XX, por muitas vezes, no entanto, pelo senso comum é utilizada de maneira generalista e mal compreendida, inclusive, há quem culpe a juventude pela onda de violência existente em nosso pais sem ao menos terem seus diretos constituídos de maneira específica, estes direitos foram somente consolidados há pouco tempo e a própria política pública de juventude que tem apenas onze anos de implementação, somos conscientes que é necessário um longo caminho para sua consolidação.

Há bem pouco tempo, nada mais que vinte e seis anos da implementação de um novo marco legal, se suscitou mudanças significativas nas políticas públicas e na proteção legal,com a aprovação do Estatuto da Criança e do Adolescente - Lei no 8.069 de 13 de julho de 1990. Esta lei busca garantir os direitos fundamentais das crianças e dos adolescentes como nunca antes visto no Brasil em outros documentos legais. Outras Leis existiram, mas tratavam as crianças e adolescentes como "problema social" e utilizavam termos pejorativos que até hoje se expressam como de menor, delinquente, vadio. 
No que concerne à categoria juventude, destacamos no texto legal, artigo 1, a definição da categoria etária da juventude no estatuto da juventude que nos diz:

\author{
CAPÍTULO I \\ DOS PRINCÍPIOS E DIRETRIZES DAS POLÍTICAS PÚBLICAS DE JUVENTUDE \\ Art. 1o Esta Lei institui o Estatuto da Juventude e dispõe sobre os direitos \\ dos jovens, os princípios e diretrizes das políticas públicas de juventude e o \\ Sistema Nacional de Juventude - SINAJUVE. \\ § 10 Para os efeitos desta Lei, são consideradas jovens as pessoas com idade \\ entre 15 (quinze) e 29 (vinte e nove) anos de idade. \\ § 20 Aos adolescentes com idade entre 15 (quinze) e 18 (dezoito) anos aplica- \\ -se a Lei no 8.069, de 13 de julho de 1990 - Estatuto da Criança e do Adoles- \\ cente, e, excepcionalmente, este Estatuto, quando não conflitar com as normas \\ de proteção integral do adolescente.
}

Os dois documentos da legislação brasileira, que norteia os debates e estudos, prevê o corte etário para identificar o quantitativo de jovens no Brasil e melhor direcionar ações. Essa delimitação estática, que não considera fatores psicológicos e sociais possibilita facilidade em saber o quantitativo de jovens, traçar um planejamento e tratar as questões políticas sociais para a juventude.

Os autores Freitas (2005); Abramo (2005); León(2005), nos apresenta inúmeros encontros do Grupo de Trabalho (GT) entre 2001-2004, onde se buscava analisar as políticas públicas de juventude no Brasil. Segundo Freitas (2005), em 2002, o GT formulou um conjunto de propostas de políticas para adolescentes de baixa escolaridade e baixa renda, debatidas em teleconferência nacional, que reuniu cerca de 1.500 participantes de todas as regiões do país. Para autora:

O conjunto das contribuições dos participantes foi sistematizado e possibilitou
a elaboração de uma publicação, apresentada aos candidatos que chegaram ao
segundo turno da eleição presidencial de 2002 . Ao longo de 2003 , as propostas
foram apresentadas aos mais diversos Ministérios (Educação, Assistência Social,
Cultura, Desenvolvimento Agrário, Esporte e Trabalho), que indicaram represen-
tantes para participarem das reuniões do Grupo Técnico. (FREITAS, 2005, p. 05)

Ao mesmo tempo em que se desenrolava esse processo, crescia no País a percepção de que era preciso elaborar políticas públicas para a juventude, para além da faixa compreendida como adolescência (Freitas, 2005). Essa percepção foi de grande importância, pois buscou ampliar no 
ano de 2005 a conceituação sobre a categoria de juventude, que até então se tinha na adolescência um referencial que envolvia mais a aproximação com as crianças como categoria social do que a juventude. Ao trabalhar as ações pensando na temática juventude se forma outras opções de como pensar a juventude, principalmente as discussões de políticas públicas para proporcionar uma maior garantia de direitos.

Freitas (2005) aborda nos trabalhos realizados pelos grupos ministeriais, o debate sobre o que é juventude e sobre o que é adolescência, vejamos:

O GT Cidadania dos Adolescentes deparou-se, então,com uma grande questão: qual a relação entre as políticas para a adolescência - até então pensadas em articulação com as políticas para a infância - e as políticas para a juventude? Ou, no fundo, qual a relação entre adolescência e juventude? Em que medida se confundem ou se diferenciam? (FREITAS, 2005, p. 06)

Destacamos o debate sobre adolescência e juventude sendo algo recente, principalmente como política pública, logo, importa destacar que a faixa etária sempre foi considerada como referência na divisão dessas categorias para compreensão do que seria a adolescência e a juventude. Por décadas os adolescentes eram referenciados mais pela aproximação com as crianças do que propriamente com a juventude, em consequência os jovens com mais de 18 anos ficaram esquecidos nos debates nas políticas públicas, o que proporcionou aos jovens maior dificuldade. As faculdades com poucas vagas, o mercado de trabalho não sinalizava abertura para os jovens, cursos técnicos públicos eram difíceis e a preocupação social em relação à juventude aumentava, principalmente na década de 1990 quando se tinha demograficamente um crescimento do público juvenil.

A ampliação da assistência à adolescência, incluindo a juventude foi fundamental para que se desenvolva um direcionamento mais amplo das políticas públicas, bem como gerar visibilidade para o debate de demandas específicas desse público. Freitas (2005), nos alerta que é necessário distinguir estes dois momentos da vida no fomento de políticas públicas:

Atualmente, uma das tendências, no interior do debate sobre políticas públicas, é distinguir como dois momentos do período de vida amplamente denominado juventude, sendo que a adolescência corresponde à primeira fase (tomando como referência a faixa etária que vai dos 12 aos 17 anos, como estabelecido pelo ECA), caracterizada principalmente pelas mudanças que marcam esta fase como um período específico de desenvolvimento de preparação para uma inserção futura; e juventude (ao que alguns agregam o qualificativo propria- 
mente dito, ou então denominam como jovens adultos, ou ainda pós adolescência) para se referir à fase posterior, de construção de trajetórias de entrada na vida social. (FREITAS, 2005, p. 08)

Uma das autoras que trabalham com a temática juventude por muitos anos no Brasil é Abramo (2005), ela compreende que o jovem deve ser analisado com um olhar que os considerem atores dinâmicos, que podem contribuir na sociedade, pois possuem potenciais para trabalharem tanto no mercado como em suas comunidades. Para Abramo (2005):

\begin{abstract}
Nessa visão, a juventude é compreendida como etapa singular do desenvolvimento pessoal e social, por onde os jovens passam a ser considerados como sujeitos de direitos e deixam de ser definidos por suas incompletudes ou desvios. Tal diretriz se desenvolve, em alguns países,depois dos anos 90, em grande medida inspirada nos paradigmas desenvolvidos no campo das políticas para a infância e para as mulheres. Muda os enfoques anteriores principalmente por superar a visão negativa sobre os jovens e gerar políticas centradas na noção de cidadania, abrindo a possibilidade da consideração dos jovens como sujeitos integrais, para os quais se fazem necessárias políticas articuladas intersetorialmente. (ABRAMO, 2005, p.22)
\end{abstract}

No Brasil se abri a possibilidade da proteção integral aos jovens como sujeito, ainda que asseverado pelo ECA e estatuto da juventude, no entanto, falta muito para consolidação da integralidade, mas devemos compreender que temos uma legislação e que podemos potencializa-las, pois os direitos são específicos e servem para proteger esse grupo particular:

Art. 3 A criança e o adolescente gozam de todos os direitos fundamentais inerentes à pessoa humana, sem prejuízo da proteção integral de que trata esta Lei, assegurando-se-Ihes, por lei ou por outros meios, todas as oportunidades e facilidades, a fim de Ihes facultar o desenvolvimento físico, mental, moral, espiritual e social, em condições de liberdade e de dignidade. (ECA.1990, p.20)

Além dos governos e da sociedade civil, percebemos que a partir dos anos 90, inicia-se nas empresas privadas, também, um processo em que se procura a juventude para integrar o corpo profissional. É certo que o Governo Federal incentivou com subsídios nas empresas em relação aos impostos para que estas, com o projeto de responsabilidade social, incluíssem os jovens, 
que não tinham experiência. Muitas empresas iniciam um processo de formação para educação e para o mundo do trabalho no próprio ambiente de trabalho possibilitando a muitos jovens uma oportunidade para além dos estágios, e, em 2014 foi lançado o Programa Nacional de Acesso ao Ensino Técnico e Emprego - Pronatec ${ }^{3}$, no qual se privilegiou cursos de capacitação em todo o Brasil aproximando ainda mais a juventude, governo e empresas, sendo então algo presente como menciona Groppo (2004).

Para o autor Groppo (2004), a juventude é uma categoria social utilizada para definir padrões, a categoria faz parte do imaginário social. A juventude é entendida como algo presente e ao mesmo tempo futuro, assim a juventude se torna fonte de inspiração para algumas sociedades e pessoas pois é capaz de normatizar comportamentos, vejamos:

\begin{abstract}
A juventude trata-se de uma categoria social usada para classificar indivíduos, normatizar comportamentos, definir direitos e deveres. É uma categoria que opera tanto no âmbito do imaginário social,quanto é um dos elementos "estruturante"das redes de sociabilidade. De modo análogo à estruturação da sociedade em classes, a modernização também criou grupos etários homogêneos,categorias etárias que orientam o comportamento social, entre elas, a juventude. (GROPPO, 2004, p.03)
\end{abstract}

Quando mencionamos as formas múltiplas de juventude, devemos compreender que elas também se identificam e se aproximam pelas suas semelhanças, porque ao se encontrarem, os jovens formam, na sociedade, alguns grupos juvenis, estes se identificam por diversos motivos, pode ser pela forma de se vestir, de falar, pelo gosto musical, pela idade semelhante, pela escola, grupo de igreja, grupo de hip hop dentre outras formas de aproximação.

Trabalho, desemprego, sexualidade, participação, protagonismo, agrupamentos, são expressões de juventude que a todo o momento são debatidos e estão permeando os meandros da juventude, devemos, então, perceber que está juventude busca o trabalho, o esporte, o lazer, a amizade, a cultura, a educação, a assistência social e tais aspectos implicam no desenvolvimento integral e formativo da juventude. A proteção social com fortalecimento de vínculos potencializa ações que são de fundamental importância para juventude, neste contexto iremos dialogar no próximo tópico a respeito das Políticas Públicas de Juventude desenvolvidas no Brasil.

O Brasil vivencia em 2016 uma desaceleração da economia que aumenta impostos, reduz o Estado nas políticas sociais e proporciona, assim, uma redução na criação de empregos, e progra-

3 Segundo o Ministério da Educação (MEC) o Programa Nacional de Acesso ao Ensino Técnico e Emprego Pronatec foi criado com o objetivo de fazer com que jovens de famílias de baixa renda tenham acesso ao ensino técnico e profissionalizante, para facilitar a busca pelo primeiro emprego. 
mas e projetos específicos, afetando, principalmente, os jovens, pois muitos não possuem experiência ou escolaridade tornando mais difícil uma colocação no mercado de trabalho como afirma o IBGE em 2016 onde existem quase 11 milhões de pessoas desempregadas atualmente, dentre elas muitos jovens.

Segundo o IBGE (2010) o Brasil tem 50,2 milhões de habitantes entre 15 e 29 anos (Estatuto de Juventude). Desses, 34 milhões têm entre 15 e 24 anos. De acordo com a Secretaria Nacional de Juventude, é nessa faixa etária que se encontra a parte da população brasileira mais atingida pelos índices de desemprego, evasão escolar, mortes por homicídio e envolvimento com drogas e com a criminalidade. Para enfrentar esses desafios, foi instituída a Política Nacional de Juventude, por meio da Medida Provisória 238, assinada em 1ํ de fevereiro de 2005. No mesmo ato, foram criadas a Secretaria Nacional de Juventude, o Conselho Nacional de Juventude, e o Programa Nacional de Inclusão de Jovens (Projovem), que em 2015 se concretizam como uma das ações governamentais, após a constituição de 1988,que concebe os jovens sujeitos de direitos e de políticas públicas a nível nacional.

Seguindo as orientações do Grupo, foi criado em 2005, a Secretaria Nacional de Juventude e o Conselho Nacional de Juventude (CONJUVE), dando um passo decisivo para a construção da política juvenil (BRASIL, 2007). Segundo a Secretaria Nacional de Juventude (SNJ) é importante ressaltar que até então a juventude era tratada, pelo Estado brasileiro, apenas como uma fase de transição da adolescência para a vida adulta. Em função do próprio ECA, as políticas para o segmento estavam restritas ao universo de jovens com idade até 18 anos e a partir desta idade o Estado os enquadrava automaticamente no segmento de adultos, com acesso às políticas universais, a exemplo daquelas voltadas para a educação e a saúde, sem qualquer reconhecimento de suas especificidades (BRASIL, 2007).

A SNJ, em seus trabalhos iniciais, apontava como maior desafio mostrar que a juventude é um segmento social com especificidades relevantes e que os jovens são não somente sujeitos de direito, mas também importantes agentes do projeto de desenvolvimento do país. Considerou fundamental que a Política Nacional de Juventude fosse uma Política efetivamente de Estado, ou seja, uma política permanente e independente de futuras correntes partidárias que venham a se estabelecer no poder executivo, tanto federal como nos estados e municípios.Importante destacar, todavia, que as ações a nível nacional fortalecem as políticas municipais pois "forçam" os gestores a entrarem com convênios para implementação dos programas, projetos e serviços em seus municípios.

Salientamos que a PNJ vem desenvolvendo ações de transversalidade, principalmente com a política de educação, esporte e assistência social. Assim percebe-se que a tentativa de incluir a pauta juventude em outras políticas públicas é de fundamental importância para o desenvolvimento de ações e projetos. $O$ trabalho conjunto na pauta da juventude possibilita, inclusive, maior viabilidade dos jovens de desenvolverem condições de se apropriar dos programas e projetos e assim terem oportunidades de serem protagonista destas políticas e de sua vida na comunidade. 
Nesse contexto, cabe à Secretaria Nacional de Juventude o papel de articular as ações dos diversos Ministérios, sob a orientação da Política Nacional de Juventude, garantindo que os programas façam frente aos desafios desse segmento, mas evitando iniciativas redundantes ou fragmentadas destes órgãos (BRASIL, 2007), nesse sentido podemos citar algumas ações conjuntas destes ministérios tais como:

\begin{abstract}
Além disso, a exemplo do que ocorre em vários estados e municípios e em outros países que adotam políticas públicas voltadas para a juventude, a Secretaria Nacional de Juventude tornou-se referência, no governo federal, para a população jovem. A Secretaria está vinculada à estrutura da Secretaria-Geral da Presidência da República e coordena o programa Projovem Integrado. Este programa foi criado em 2007 a partir da unificação de outras seis iniciativas voltadas para o público juvenil. O Projovem Integrado atua por meio de quatro modalidades, executadas pela Secretaria Nacional de Juventude (Projovem Urbano); Ministério da Educação (Projovem Campo);Ministério do Desenvolvimento Social e Combate à Fome (Projovem Adolescente); e o Ministério do Trabalho e Emprego (Projovem Trabalhador). (BRASIL, 2007, p.173)
\end{abstract}

Além da secretaria, podemos destacar outra ferramenta que proporcionaram às políticas de juventude uma maior participação nas discussões e debates nas políticas públicas, o CONJUVE no qual objetivo principal é de acompanhar a política e propor seu fortalecimento, podendo realizar estudos, propor ações e acompanhar os resultados das políticas públicas de juventude.

Diferente de outros conselhos de direito que são paritários e que há uma composição formada pela sociedade civil em meia parte e a outra metade indicada pelos governos, No CONJUVE a sociedade civil é a maioria, em torno de dois terços, e isso é muito importante nas discussões das políticas a nível nacional, estadual e municipal, por possibilitar maior participação de membros interessados da sociedade que se configuram o objeto das políticas. A criação do conselho a nível nacional se torna uma cascada nos estados e municípios, sendo assim obrigatório para as gestões organizarem na sociedade e entre as secretarias uma articulação para que se possam formar os conselhos municipais.

O Conselho tenta implementar o termo juventudes ${ }^{4}$, pois lá participam negros, indígenas, jovens de movimentos religiosos, jovens rurais e urbanos enfim, uma parcela plural da população

4 Para Oscar Dávila León, no artigo "Adolescência e juventude: das noções e abordagens”, da publicação da ação Educativa, com o fortalecimento do debate acerca da adolescência e juventude, surge também a necessidade de pluralizar os termos para se referir a tais coletivos sociais, referindo-se a essas fases como "adolescências" e/ou juventudes", o que mostra de forma mais consistente a heterogeinidade que ocorre nesta fase, pois como dito acima, esse período ocorre de forma diferente para cada um - que vai depender do cotidiano, local onde o sujeito vive e circunstâncias da vida, classes sociais e contextos sócio-culturais. 
com especificidades por vezes distintas, mas que têm muito a contribuir neste processo de participação social indicando suas demandas e assim possibilitar o tão sonhado protagonismo juvenil. Assim, o conselho se destaca como mais uma ferramenta de consolidação desta política, ele é assim constituído:

\begin{abstract}
O Conselho é composto por $1 / 3$ de representantes do poder público e $2 / 3$ da sociedade civil, contando, ao todo, com 60 membros, sendo 20 do governo federal e 40 da sociedade civil.A representação do poder público contempla, além da Secretaria Nacional de Juventude,todos os Ministérios que possuem programas voltados para os jovens: a Frente Parlamentar de Políticas para a Juventude da Câmara dos Deputados, o Fórum Nacional de Gestores Estaduais de Juventude, além das Associações de Prefeitos. Essa composição foi estruturada deforma que as ações para a juventude sejam articuladas em todas as esferas governamentais(federal, estadual e municipal), o que contribuirá para consolidação da Política Nacional de Juventude como uma política do Estado brasileiro. (Brasil, 2007, p.174)
\end{abstract}

Dentre os muitos desafios da política de juventude, são trabalhadas a nível nacional, cinco dimensões que a política nacional de juventude articula que são: a inclusão, participação, dimensão institucional, internacional e o marco legal. Segundo o IBGE (2010), existem ainda 4,5 milhões de jovens entre 15 e 29 anos fora da escola, do mercado de trabalho e sem acesso aos bens culturais e ao esporte.

O Projeto de Lei 4530 / 2004 acrescenta:

Plano Nacional de Juventude (PL 4530/2004) - O texto da PEC 042/2008 sugere ainda a necessidade de aprovação do Plano Nacional de Juventude (PL 4530/2004). O Plano conduziria o país por um conjunto de metas sobre os direitos dos jovens, que deverá ser cumprido nos próximos dez anos pela União, em parceria com estados, municípios e organizações juvenis, envolvendo ações das mais diversas áreas, como cultura, saúde, esporte, cidadania,trabalho, inclusão digital e educação, entre outros.(Brasil, 2007, p.184)

Somando-se a emenda constitucional e ao projeto de lei supramencionado, o terceiro marco regulatório da Política Nacional de Juventude é o Estatuto de Juventude, no qual se fala em emancipação.Esta Lei, 12.852 de 05 de agosto de 2013, é a que garante a participação dos jovens na formulação de políticas públicas, bem como os recursos ao programas e serviços: 
O documento regulamenta os direitos dos brasileiros entre 15 e 29 anos e determina que é obrigação da família, da comunidade, da sociedade e do poder público assegurar diversos direitos aos jovens como o direito à participação social e política, à igualdade racial e de gênero, à saúde e sexualidade, à educação e representação juvenil, à profissionalização e ao trabalho, entre outros. (BRASIL, 2007, p.184)

Esses debates, ainda mais embrionários, são de fundamental importância para levar a compreender que a juventude necessitava de um olhar focado em suas necessidades, que são bem especificas. Após as academias iniciarem o debate, o congresso nacional também leva a temática juventude para as comissões e, em 2003, o debate sobre a Proposta de Emenda Constitucional (PEC), de no 138, conhecida como PEC da Juventude, foi aprovada em 2010. Somente, no entanto, em 05 de agosto de 2013, pela Lei 12.852, foi aprovado o Estatuto de Juventude.

Percebe-se que o debate sobre políticas públicas de juventude é bem amplo nos dias atuais, porém, existem ainda muito estereótipos que associam a imagem dos jovens a violências. É constante o senso comum afirmar que é a juventude a causadora maior da violência, logo, o desafio das políticas públicas atuais é, também, alcançar o envolvimento do maior número de jovens e continuar oferecendo inúmeras atividades de fomento a cidadania e inclusão social. Compreendemos que foram explicitados os primeiros passos de como as políticas públicas de juventude foram se constituindo e se efetivando, em especial a partir de 2005, com a criação do Conselho Nacional de Juventude e da Secretaria Nacional de Juventude, percebemos assim sua construção no Brasil como política de direitos.

\section{Considerações Finais}

Neste trabalho, apresentamos a política de Assistência Social e Juventude que ao longo de onze anos tem um impacto na vida dos jovens do Brasil, mas percebemos o quão distante ainda estamos em relação à qualidade ideal. $O$ estado deve primeiro compreender as especificidades da condição juvenil, ouvir os jovens, perceber como muitos direitos fundamentais estão sendo violados a todo instante. O objetivo deste estudo foi apresentar a construção ao longo dos últimos onze anos das políticas públicas já citadas, a pesquisa contribuiu não apenas com a produção teórica, mas possibilitou reflexões e novos delineamentos na efetivação prática dessa política social no Brasil.

Apresentamos neste artigo o Serviço de Convivência Adolescente uma ação de política pública voltada para nossa juventude capitaneada pela proteção social básica, proteção esta de 
grande importância na política de assistência social por desenvolver atividades culturais, esportivas e socioeducativas para nossas juventudes. $\mathrm{O}$ atendimento a este segmento da sociedade é de fundamental importância pelo seu trabalho ético, pautado na defesa dos direitos humanos. O foco no segmento juvenil demonstra todo um cuidado para uma das camadas que se apresenta em vulnerabilidade.

A partir deste trabalho percebemos que desde o marco histórico e de construção das normativas das duas políticas pode-se afirmar que a Política de Juventude e Assistência Social terão ainda grandes desafios a serem políticas de direito para a população e um dever do Estado, cabendo a este a execução de ações que visem à garantia da cidadania e da satisfação das necessidades sociais, principalmente daquela parcela da população que historicamente ficou a mercê da boa vontade dos grupos político-econômicos hegemônicos.

Tanto a Política Pública de Juventude como a Política Nacional de Assistência Social apresenta-se como um dispositivo legal que busca direcionar ações para a área social e de juventudes e assim fortalecer as Políticas Públicas com ações articuladas tanto com recursos financeiros como humanos proporcionando aos níveis de Governos (Federal, Estadual e Municipal) uma melhor articulação de propostas de Estado e não somente de um governo.

No presente artigo percebemos que ainda existe a necessidade do fortalecimento das ações socioeducativas no âmbito da Política de Assistência Social materializada no SUAS e no Plano Nacional de Juventude também materializado no Estação Juventude como em seu Estatuto de Juventude. Tendo em vista que estas possibilitam a autonomia dos sujeitos em especial dos jovens, os autores e normativas proporcionam um entendimento em que as juventudes possam ter em si a participação política e o exercício da cidadania através do fortalecimento dos vínculos familiares e comunitários e na participação de conselhos de direito como da Assistência Social e o de Juventude.

A participação das juventudes é fundamental na compreensão da vida diária, algumas vezes os movimentos sociais e escolares como os grêmios são mais interessantes do que ficar sentado em uma cadeira um período onde muitas vezes não se aprende nada, assim a juventude rompe com práticas tuteladoras e hierarquizadas, é através do fortalecimento destes espaços da assistência social e da política pública de juventude que é possível fazer frente ao modelo de políticas públicas que vem sendo ditado pelo capital e pela lógica do capital que reduz o direito social ao repasse de recursos financeiros prejudicando a realização dos serviços como observamos hoje coma PEC 55 (Senado Federal - gastos públicos) e a reforma do ensino médio.

Ao longo do trabalho apresentamos o SUAS e como se organiza com ações da Assistência Social (em dois tipos de proteção social) a primeira é a Proteção Social Básica, destinada à prevenção de riscos sociais e pessoais, por meio da oferta de programas, projetos, serviços e benefícios a indivíduos e famílias em situação de vulnerabilidade social, no artigo destacamos o Serviço de Proteção e Atendimento Integral à Família (PAIF) e o Serviço de Convivência e Fortalecimento de Vínculos (SCFV) e em especial ao Serviço de Convivência Adolescente. 
Apresentamos a Proteção Social Especial, destinada a famílias e indivíduos que já se encontram em situação de risco e que tiveram seus direitos violados por ocorrência de abandono, maus-tratos, abuso sexual, uso de drogas, entre outros aspectos. No Brasil destacamos como unidade da Especial o Centro de Referência Especializado de Assistência Social (CREAS), Centro -Pop para moradores em Situação de Rua e o Abrigo Domiciliar.

Destacamos no artigo o Serviço de Convivência como um serviço de grande importância, tanto para a política de Assistência Social como para a política de Juventude, pois reforça o fortalecimento dos vínculos familiares, o direito de brincar, o direito de ser jovem, de ser adolescente. As ações de socialização e de sensibilização para a defesa dos direitos das crianças, dos direitos dos adolescentes são a tônica das atividades desenvolvidas pelos profissionais.

Por isso a importância das políticas públicas de juventude integradas à Assistência Social por possibilitar discutir a juventude em relação à sua família e comunidade, em seu contexto social. Ao longo dos anos estamos observando o país passar por mudanças políticas em favor da juventude e ao analisar as políticas públicas como o Serviço de Convivência Adolescente (Projovem Adolescente) e assim devemos entender a relação existente entre o Estado e as políticas de juventude que este implanta e em muitos casos em implementação em muitas cidades no Brasil.

Finalizamos afirmando que as políticas de Assistência Social e de Juventude proporciona dentro das normativas uma vida social para os jovens, essa vida social é de grande importância, analisamos que é a sociabilidade buscada pela juventude, pois o jovem necessita se integrar, principalmente os adolescentes que estão saindo da infância para fase adulta. Estes são os desafios: integrar além dos jovens, as políticas de juventude, assistência social dentre outras políticas como trabalho e educação que são importantes no processo intersetorial. Como percebemos ao longo dos últimos onze anos, ambas às políticas tiveram seu crescimento tanto a nível nacional como municipal, agora o caminho é o do desenvolvimento, aprimoramento e articulação para que estas políticas sejam potencializadas e que as juventudes sejam chamadas para contribuir na construção dos próximos dez anos na efetivação das políticas públicas como direitos fundamentais a juventude brasileira. 


\section{Referências}

ABRAMO. Helena Wendel. Considerações sobre a tematização da juventude no Brasil. In: Revista Brasileira de Educação. São Paulo: ANPED, 1997.

ABRAMO, Helena Wendel; MORIN, Edgar. Considerações sobre a tematização da juventude no Brasil. In: Revista Brasileira de Educação. São Paulo: ANPED, 1997.

ABRAMO, Helena Wendel; FREITAS, Maria Virginia de; LEON,Oscar Dávila. Juventude e Adolescência no Brasil: referências conceituais. São Paulo: Ed. Ação Educativa, 2005. BOURDIEU, P. Introdução a uma sociologia reflexiva In: O Poder Simbólico. 2. ed. Rio de Janeiro: Bertrand Brasil, 1999.

BRASIL. Constituição da República Federativa do Brasil de 1988. Brasília: Senado Federal, 2004. Ministério do Desenvolvimento Social e Combate à Fome. Política Nacional de Assistência Social 2004. Brasília, 2005.

Decreto no 6.135, de 26 de junho de 2007. Dispõe sobre o Cadastro Único para programas sociais do Governo Federal e dá outras providências. Brasília 2007.

Ministério do Desenvolvimento Social e Combate à Fome. Reordeamento Serviço de Convivência - perguntas e respostas - Brasília: 2014.

Lei Orgânica de Assistência Social. Lei no 8. 742/93. Brasília: Ministério do Desenvolvimento Social e Combate à Fome, 2003.

IBGE. Diretoria de pesquisas, coordenação de trabalho e rendimento. Pesquisa Nacional por Amostra de Domicílios Contínua - PNAD Contínua (2015). Brasilia, 2016. 
Estatuto da criança e do adolescente. Lei Federal no 8.069, de 13 de julho de 1990. Fortaleza: IOCE, 1991.

CASTRO, Mary Garcia. Políticas Públicas por identidades e de ações afirmativas: acessando gênero e raça, na classe, focalizando juventudes. São Paulo: Unesco. 2004.

DAYRELL, Juarez. Juventude, grupos de estilo e identidade. Educação em Revista, n. 30, p. 25-39, dez. 1999.

FALEIROS. Vicente de Paula, 1941. A Política Social do Estado Capitalista: as funções da Previdência e Assistência Social. São Paulo: Cortez 12. ed, 2009.

FREITAS, M.V. (Org.) Juventude e adolescência no Brasil: referências conceituais. São Paulo: Ação Educativa, 2005.

GEOVANNI, Levi; CLAUDE, Jean. História dos Jovens. São Paulo: Companhia das Letras. 1996. GIL, Antônio Carlos. Métodos e Técnicas da pesquisa social. 6. ed. São Paulo, SP: Atlas, 2008.

GROPPO, Luís Antônio. Dialética das juventudes modernas e contemporâneas. Revista de Educação do Cogeime, Ano 13 - n.25, dez / 2004. NOVAES, Regina. Política Nacional de Juventude: diretrizes e perspectivas. São Paulo: Conselho Nacional de Juventude (CONJUVE); Fundação Friederich Ebert, 2006.

SPOSITO, Marilia Pontes. Os jovens no Brasil: desigualdades multiplicadas e novas demandas políticas. São Paulo: Ação Educativa, 2003. 